\title{
FAZER O CERTO
}

Historicamente, a corrupção sempre foi um assunto vinculado a agentes públicos e políticos desonestos que se valem do cargo para vender competências públicas ou que, mediante extorsão, obrigam particulares a pagar pelos serviços que deveria prestar. Esta narrativa corresponde ao argumento empresarial de que não resta outra alternativa, se se quiser fazer negócios no Brasil, senão entrar no círculo vicioso do suborno, como fazem todos, raciocínio que assume a corrupção como uma espécie de tributo ou pedágio que simplesmente integra toda e qualquer transação. Parece absurdo, mas até recentemente, países como a Alemanha permitiam que, na declaração de renda tributável das empresas, fossem deduzidas despesas com o pagamento de propinas pagas em outros países, para obter licenças. Tal regra seguia uma doutrina tão antiga quanto equivocada de que a corrupção permite destravar exigências burocráticas, agilizando a realização de negócios e estimulando o crescimento econômico. ${ }^{214}$

A aceitação dessa espécie de taxa da corrupção se reflete no discurso do advogado de um lobista envolvido na Operação Lava-Jato, ao afirmar em uma entrevista que "se não fizer acerto [com políticos], não coloca um paralelepípedo no chão". 215

214 BLOOMBERG. Germany, where bribery is tax deductible. Disponível em: <https://www. bloomberg.com/news/articles/1995-08-06/germany-where-bribery-is-tax-deductible-intl-edition>. Acesso em: 30 jun. 2017.

215 GONÇALVES, André. Sem propina, não se coloca um paralelepípedo em obra pública, diz advogado. Correio Braziliense. Disponível em: <http://www.gazetadopovo.com.br/blogs/ 
Os casos de corrupção e ineficiência que diariamente vêm à tona jogam luz sobre uma prática mais ampla de dominação social, tal seja, a aliança entre o poder econômico (empresas) e o poder público (políticos e burocratas), que é uma faca de dois gumes, onde cada lado busca maximizar os próprios interesses em detrimento do patrimônio do estado. Verdadeiro capitalismo de laços que forma um coquetel explosivo composto por favores oficiais, boas oportunidades de negócios em um ambiente de governança débil, políticos decididos a sugar os cofres do Estado, sistemas de controle frágeis e um seleto grupo de empresas que competem entre si a repartição do patrimônio público. Os resultados (infelizmente) são familiares: aguda ineficiência dos gastos governamentais, pois quando a administração outorga a construção da escola à empresa que ofertou maior vantagem por vias transversas, está ignorando propostas potencialmente melhores, e a corrupção sistêmica e estrutural, modeladora dos tipos de relação entre Estado e empresas.

Tais práticas não estão restritas às relações com o setor público. Em geral, a forma de fazer negócios tornou-se poluída. Quando práticas sujas se convertem na regra, aquele que joga limpo será engolido pela competição injusta. Dentro do círculo vicioso, o incentivo é trapacear, esperando que os demais hajam da mesma forma.

Deste modo, onde existe um quadro-geral de corrupção, os não corruptos são levados a conspirar com ela, ou ao menos aceitá-la, de modo a não ficar de fora do sistema de vantagens. Esse mercado político clandestino cria uma estrutura de normas invisíveis mais poderosas do que as próprias leis do Estado, já que essas últimas poderiam ser violadas com impunidade, enquanto qualquer um que desafiasse as convenções do mercado ilícito encontraria punição certa. Nestas circunstâncias, o interesse de todos os atores consiste em aceitar o status quo, recebendo ou pagando propinas. Bem, se todo mundo aparenta ser corrupto, por que eu não deveria sê-lo? ${ }^{216}$

A corrupção envolvendo o setor privado é um problema complexo. Em uma perspectiva macro, ela distorce os mecanismos tradicionais de mercado, como a competição justa, gerando custos adicionais às transações. Segundo o Fórum Econômico Mundial, a corrupção aumenta em $10 \%$ o custo na realização de negócios, sem falar no risco de penalidades e danos reputacionais. Só agora, com as revelaçóes proporcionadas por investigaçóes mais rigorosas, as companhias começam a

conexao-brasilia/sem-propina-nao-se-coloca-um-paralelepipedo-em-obra-publica-diz-advogado-quem-vai-dizer-que-ele-esta-errado/>. Acesso em: 15 jun. 2017.

216 DELLAPORTA, Donatella; VANUCCI, Alberto. Corrupt exchanges: actors, resources and mechanisms of political corruption. Nova York: Aldine de Gruyter, 1999. 
enfrentar os resultados negativos advindos da inobservância de valores éticos: além das punições no âmbito criminal, forte impacto reputacional e nas finanças. $\mathrm{O}$ banco de investimento brasileiro, BTG Pactual, por exemplo, devido à prisão de seu então executivo-chefe no âmbito da Operação Lava Jato, em 2015, perdeu mais de $60 \%$ das ações na bolsa de valores. ${ }^{217}$

Contaminadas como estão as regras do jogo, seria possível promover alguma transformação ética? Mais uma questão complicada que devemos superar.

$\mathrm{Na}$ linha do que venho afirmando nos capítulos anteriores, os atores dificilmente mudarão o seu comportamento apenas em função de mudanças incrementais, que acirrem os mecanismos de repressão e punição, embora elas sejam indubitavelmente necessárias. A impunidade ainda é latente e ela compromete bastante a eficácia desse tipo de medida. O custo é baixo e as oportunidades, volumosas. É como apertar sucessivas vezes o botão do elevador na espera de que ele chegue mais rápido ao nosso encontro.

Diante dessas circunstâncias, resta evidente que o setor privado terá de promover esforços para uma efetiva mudança de cultura. É essencial que as empresas atuem com honestidade, adotando medidas preventivas que ajudem o Estado no esclarecimento da corrupção, e valorizem a ética como única forma possível de operar. Se falamos da ética individual no último capítulo (reportante), agora nos referimos à ética corporativa. Esse movimento de privatização do enfrentamento à corrupção, crescente na última década mundo afora, busca primariamente reduzir os incentivos que ensejam desvios, fraudes e ineficiências, bem como estimular o comportamento correto.

Uma empresa, dada sua natureza de ficção jurídica, não age por si mesma, por vontade própria, senão a partir da atuação humana e, justamente por isso, está sujeita a erros, pressões, influências e agentes mal-intencionados. Em bom português: qualquer organização está sob permanente risco de agir corruptamente (oportunidades de violação). Não é algo que possa ser inteiramente evitado, sobretudo porque vivemos em uma sociedade de risco, onde prevalece a imprevisibilidade. Assim, é impossível eliminar todos os riscos do sistema, tampouco garantir que sejam completamente controlados. Segurança absoluta é ambiente que nem a ciência natural arrisca adentrar.

Especialmente no âmbito corporativo, alguns fatores aprofundam estes riscos: a cultura empresarial do lucro de curto-prazo, pregada pelas principais escolas de

217 Attracta Mooney, BTG pactual: Brazil is like "house of cards" on acid. Financial Times. Disponível em: <https://www.ft.com/content/c22e267c-5056-11e7-bfb8-997009366969?mhq5j=el>. Acesso em: 28 jun. 2017. 
negócios do mundo, segundo a qual a única responsabilidade social das corporações é aumentar seus lucros e valorizar suas açōes no mercado, está intimamente associada à prática da corrupção, pois a busca pelo retorno econômico rápido se dá, na maioria das vezes, em sacrifício às normas éticas, reduzindo a gestão ao mínimo limite moral. Interessante notar, como fez o professor de Harvard Eugene Soltes, ao entrevistar executivos processados ou presos por crimes do colarinho branco, que muitos deles pensavam estar tomando atitudes acertadas no interesse das empresas. $^{218}$ Estas pessoas, ignorando a dimensão ética de suas condutas, tomaram atitudes imorais convencendo-se de que estavam fazendo a coisa certa, efeito que alguns especialistas chamam de cegueira ética ${ }^{219}$ ou ponto-cego ético. ${ }^{220}$ Além do mais, esse tipo de pressão intensifica-se com o estabelecimento de remunerações vinculadas à performance (stock options), acarretando, por um lado, a obsessão por resultados bimestrais em detrimento de benefícios duradouros e, por outro, o desestímulo em obedecer padrōes éticos.

As controversas pesquisas sobre psicologia da autoridade e até que ponto as pessoas contrariam seus princípios morais em razão da obediência hierárquica, conduzidas por Stanley Milgram, na década de 1980, ajudam a demonstrar a falta de clareza na delimitação da consciência ética.

A questão central, portanto, é buscar os caminhos para controlar e reduzir os riscos, tanto em termos de probabilidade de sua ocorrência, quanto no tocante ao impacto que eles causariam nas atividades da organização. Isto impóe desenvolver-se um controle ético dos riscos que funcione como primeira linha de defesa contra desvios e má-gestão. Essa é a tarefa dos programas de compliance. Sim, outro termo estrangeiro de pronúncia complicada, mas que desde logo chamarei de conformidade ou integridade ao longo do capítulo, por duas razões: a uma, para facilitar a compreensão e a nossa vida daqui em diante; a duas, porque é a nomenclatura utilizada na legislação brasileira (art. 18, inc. V, do Decreto n. 8.420/2015). A ideia é mais simples do que o termo, e pode ser resumida na seguinte questão: você está agindo em conformidade (in compliance) às normas legais e éticas?

218 SOLTES, Eugene. Why they do it: inside the mind of the whit-collar criminal. Nova Iorque: Public. Affairs, 2016.

219 Argumenta-se que a cegueira ética resulta de interações complexas entre atividades individuais e de fatores contextuais. PALAZZO, Guido; KRINGS, Franciska; HOFFRAGE, Ulrich. Ethical Blindness. Journal of Business Ethics, 109:323-338.

220 SEZER, Ovul; GINO, Francesca; BAZERMAN, Max. Ethical Blind Spots: explaining unintentional unethical behavior. Harvard University. Current Opinion in Psychology, n. 6, p. 7781, 2015. 


\section{Origem e conceito do compliance: governança corporativa e responsabilidade social da empresa}

O termo compliance é uma derivação do verbo inglês to comply, que significa basicamente estar em conformidade, cumprir, satisfazer ao que fora imposto. No ambiente corporativo, a expressão é entendida como o ato de cumprir princípios éticos e regulamentos internos e externos, a fim de reduzir o risco de violação dessas normas. ${ }^{221}$

Mas, considerando que num Estado de Direito todos devem cumprir as leis, o que há de novo neste conceito? De forma simples, a conformidade aqui referida vai além da observância legal, significando, por um lado, o conjunto de medidas internas voltadas à prevenção dos riscos de transgressão, por outro, um sistema de fomento à integridade corporativa. ${ }^{222}$

Nesse sentido, o compliance se aproxima da noção de governança corporativa, expressão tão utilizada quanto mal compreendida, que traduz as boas práticas associadas à responsabilidade social da empresa. Cada vez mais, exige-se das empresas uma ética de caráter público, que pode também ser traduzida em ética privada em público, cuja finalidade não seja exclusivamente engordar o bolso dos seus administradores, menosprezando a repercussão social das operações e seus efeitos sobre terceiros interessados (stakeholders). O bom comportamento das organizações empresariais, além de aumentar os lucros, gera interesse público.

Como eliminar todos os riscos é algo impraticável, é importante entender que adotar um programa de conformidade ou compliance não garantirá a purificação total da organização, de modo que desapareçam as violações e floresça daí um ambiente de santidade e altruísmo. Uma parcela de risco é inerente ao sistema e indivíduos mal-intencionados sempre encontram (e encontrarão) oportunidades para transgredir valores morais. Por outro lado, caso os desvios éticos de fato ocorram, o programa permite a identificação e consequente correção do problema internamente. 223

221 COIMBRA, Marcelo de Aguiar; MANZI, Vanessa A. Manual de compliance. Preservando a boa governança e a integridade das organizações. São Paulo: Atlas, 2010, p. 2.

222 CONSELHO ADMINISTRATIVO DE DEFESA ECONÔMICA (CADE). Guia: Programa de Compliance - Orientações sobre estruturação e benefícios da adoção dos programas de compliance concorrencial. Janeiro, 2016.

223 GABARDO, Emerson; MORETTINI E CASTELLA, Gabriel. A nova lei anticorrupção e a importância do compliance para as empresas que se relacionam com a administração pública. A\&C - Revista de Direito Administrativo e Constitucional. Belo Horizonte, ano 15, n. 60, p. 129-147. 
Portanto, a importância da conformidade se situa nestes dois pontos: primeiro, na redução dos riscos, prevenindo-os antes que se convertam em violaçóes sistêmicas e graves, evitando custos adicionais com multas, honorários e outras puniçôes na esfera administrativa e judicial. Segundo, na deteç̧ão ligeira dos desvios perpetrados, possibilitando tanto uma resposta rápida e adequada, quanto o aprendizado sobre as áreas desalinhadas que reclamam aperfeiçoamento ético (loopings informativos de feedback). Para mais, o fomento à integridade organizacional atrai credibilidade e gera benefícios relevantes para reputação da empresa, considerando os severos danos à imagem que decorrem da simples deflagração do procedimento de investigação judiciária.

Embora tenha ganhado repercussão apenas recentemente no Brasil, os programas de conformidade surgem na transição dos anos 1960 a 1970, durante a implementação das reformas neoliberais, nos Estados Unidos, através das quais diversos serviços públicos, até então executados pelo governo, passaram a serem prestados por agentes privados. Nesse contexto, a figura do estado-provedor de bens e serviços foi paulatinamente substituído pelo estado-regulador, que regulamenta a atuação do mercado por intermédio das agências reguladoras.

A constatação posterior de que a maioria das multinacionais norte-americanas estava pagando milhôes de dólares em propinas para agentes públicos e reguladores, e a culminância do escândalo conhecido como Watergate, despertou a necessidade de adotar uma nova política anticorrupção, focada nos delitos empresariais. Como resposta, o Congresso americano aprovou o Foreign Corrupt Practices Act, de 1977 (FCPA), objetivando reforçar a conduta preventiva das corporações, ao viabilizar a responsabilidade criminal e extraterritorial das empresas, o que não era possível anteriormente.

O cenário agora era outro. Uma vez que a empresa poderia ser condenada criminalmente por delitos cometidos por seus funcionários, havia então uma pressão efetiva para que ela mesma elaborasse regulamentos a fim de adequar a conduta de seus membros às normas legais e éticas. Se os agentes econômicos funcionam a partir de incentivos, este era um baita incentivo para operar de forma ética.

O Estado, por sua vez, reconhecendo a sua incapacidade de prevenir e corrigir de forma eficaz todos os possíveis desvios legais, passou a bola às companhias para que elas promovessem autorregulações e medidas internas com este intuito. $\mathrm{O}$ equilíbrio entre normas estatais (poderes executivo e legislativo) e as regulações germinadas na empresa (códigos de conduta), é que convencionou-se chamar de autorregulação regulada. ${ }^{224}$

${ }^{224}$ GARDELLA, Darnaculleta I. Derecho administrativo y autorregulación: la autorregulación regulada. Universidad de Girona, 2002. 
Este movimento de privatização do enfrentamento à corrupção entrou na pauta das organizações internacionais, que passaram a exigir dos Estados-membros a impulsão de medidas preventivas internas no setor privado, a exemplo do que prevê o a Convenção das Nações Unidas contra a Corrupção, da ONU. ${ }^{225}$

Desde então, diversos países têm buscado estimular a implantação de condutas preventivas no habitat das corporaçōes. Mais recentemente, o Reino Unido, através do Bribery Act, de 2010, estabeleceu como crime autônomo aplicável às empresas a "falha na organização comercial em prevenir a corrupção". A criminalização dessa espécie de omissão qualificada foi responsável por promover uma onda de transformações nas empresas britânicas, que se apressaram para criar procedimentos de conformidade. ${ }^{226}$

Entretanto, se houve incentivos de caráter negativos, como a possibilidade de condenação das pessoas jurídicas e seus dirigentes, a adoção do compliance também seguiu uma linha de incentivos positivos, recompensando a elaboração de programas comprovadamente eficientes. Ambas as formas de estímulo decorrem do modelo teórico que estuda a racionalidade do comportamento criminoso. Segundo este modelo, capitaneado pelo economista Gary Becker, a conduta do agente infrator está alicerçada numa lógica de custos e benefícios, incluindo variáveis como a possibilidade de detecção, a gravidade e certeza da punição e a premiação da virtude. ${ }^{227}$ Este cálculo fizera com que os programas de compliance valessem a pena, aumentando, a um só tempo, os custos da corrupção e os benefícios da conduta ética.

Por conseguinte, a exigência de implementação do sistema de integridade é quase sempre acompanhada de recompensas pela demonstração de que o programa está funcionando adequadamente. Em alguns casos, a comprovação da eficiência do compliance permite à empresa firmar um acordo de não persecução criminal, pelo qual o Ministério Público se abstém de apresentar denúncia sobre determinadas infrações, como ocorre nos Estados Unidos, onde boa parte das investigaçôes são suspensas em decorrência dos non prosecution agreement firmados com a promotoria. Previsão semelhante foi adotada na Espanha, onde há dispositivo expresso

225 Convenção das Nações Unidas contra a Corrupção, ratificada no Brasil pelo Decreto n. 5.687/2006: art. 12, item 1 .

${ }^{226}$ MOHALLEM, Michael Freitas; RAGAZZO, Carlos Emmanuel. Diálogo institucional: primeiros passos para um plano nacional anticorrupção. Rio de Janeiro: Escola de Direito do Rio de Janeiro da Fundação Getúlio Vargas, 2017.

227 BECKER, Gary. Crime and punishment: an economic approach. Chicago: National Bureau of Economic Research, 1974. 
-• Finanças públicas: travessia entre o passado e o futuro

no Código Penal Espanhol determinando que a pessoa jurídica ficará isenta de responsabilidade caso cumpra determinadas condições nele previstas, relacionadas à eficácia das medidas de prevenção. ${ }^{228}$ Em outros ordenamentos, descabe a isenção completa de responsabilidade, conquanto a comprovada eficácia do programa de conformidade permita aliviar as penalidades eventualmente aplicadas. É o caso brasileiro.

Por aqui, o sistema de integridade já é uma realidade ao menos desde 1998, especialmente quanto à prevenção do crime de lavagem de dinheiro. Isso porque a Lei n. 9.613/98, ${ }^{229}$ exige que determinadas pessoas jurídicas que atuam no setor financeiro adotem políticas, procedimentos e controles internos que permitam adequar-se às regras sobre operaçôes financeiras, sob pena de multa. $\mathrm{O}$ dispositivo, entretanto, ao utilizar conceitos indeterminados, pouco diz sobre que políticas e procedimentos seriam esses.

$\mathrm{O}$ interesse real pelo compliance anticorrupção surge com vigor apenas em 2013, com a promulgação da chamada Lei Anticorrupção (Lei n. 12.846/2013), que possibilitou a responsabilização administrativa e civil objetiva das pessoas jurídicas, prevendo que a implementação de procedimentos internos de integridade seria levada em consideração para reduzir as penalidades administrativas previstas na lei.

Alguns fatores ajudam a explicar a ascensão (tardia) deste instituto no Brasil. Primeiro, a pressão internacional exercida principalmente pela OCDE, no cumprimento da Convenção sobre Combate à Corrupção de Funcionários Estrangeiros em Transações Comerciais Internacionais, ao constatar que o legislativo brasileiro era renitente no tocante à responsabilização das empresas. Vale lembrar que a incorporação desta convenção, pelo Brasil, gerou o compromisso do país em adequar-se às recomendações ali escritas. Segundo, a conjuntura da época, marcada pelas condenações no escândalo do Mensalão, que descortinaram o entrelaçamento corrupto entre os poderes da República, e pelas manifestações populares de junho de 2013, que reivindicava, dentre outras coisas, mais decência pública e controle da corrupção, tornando a elaboração da Lei Anticorrupção - além da Lei de Organizaçôes Criminosas (Lei n. 12.850/2013) - uma espécie de resposta a estas

${ }^{228}$ Art. 31, bis. 2, do Código Penal Espanhol. Ademais, o Tribunal Supremo da Espanha, Decisão n. 154/2016, de 29 de fevereiro, deixou assente que: "a presença de adequados mecanismos de controle supõe a existência de uma causa de justificação que exime de responsabilidade a pessoa jurídica (...)”. Além destes, Itália, Áustria, Holanda e Reino Unido também adotam sistemáticas semelhantes.

${ }^{229}$ A Lei n. 9.613/98, foi alterada pela Lei n. 12.683/2012, de modo a ampliar os deveres de compliance. 
circunstâncias. Além do mais, a eclosão da Operação Lava-Jato, mostrando a natureza corrupta das relaçóes entre o poder público e as grandes empresas brasileiras, fez do compliance o termo da moda.

O desenvolvimento da integridade no Brasil, portanto, não foi voluntário, mas fruto das circunstâncias bélicas que marcaram o início da década. Tal constatação é importante porque a inovação legislativa tem pouquíssima efetividade prática se não estiver acompanhada da mudança de valores. O programa não terá maiores resultados se não incutir a importância de se fazer a coisa certa, pelos motivos certos. $\mathrm{Na}$ terra em que o jeitinho é disseminado como forma de escapar da lei, a integridade é um objetivo ambicioso. A superação de adágios como a Lei de Gérson ou o conformismo do sempre-foi-assim são, portanto, determinantes para o sucesso do compliance. Caso contrário, o mais provável é que o programa seja visto como um entrave às metas da empresa, uma vez que contraria os procedimentos imorais consolidados pelo método sempre foi assim. É isso que precisa mudar! Seguir as regras e fomentar o comportamento ético não deve ser desvantagem competitiva, mas exigência do próprio mercado, de maneira que contar com medidas de prevenção condicione a realização de negócios e a participação no jogo. ${ }^{230}$

Quando a implementação ocorre num contexto cultural desfavorável como o nosso, o resultado provável é a criação de programas de fachada (sham programs), criados apenas para dissimular comprometimento ético. Monta-se uma estrutura superficial, uma máscara de integridade, quando na verdade não há qualquer preocupação de fato com a efetividade das medidas adotadas. É como na estória de Pompeia Sila, mulher do ditador romano Júlio César, condenada por adultério sem quaisquer provas da traição. Se, para ela, não bastava ser honesta, pois deveria parecer honesta, para as companhias que simulam programas de compliance, basta a aparência de honestidade. Por isso é recorrente a afirmação segundo a qual, no Brasil, o compliance despertou muito entusiasmo, porém pouca implementação.

À Operação Lava-Jato reconhece-se o mérito de ter jogado luz sobre esses programas para inglês ver, adotados pelas grandes empresas envolvidas em corrupção. A Organização Odebrecht, por exemplo, que estava no cerne da estrutura de desvios revelada pela operação, possuía um programa de integridade desde 2014, mesmo mantendo um setor específico voltado à concessão e contabilização de propinas: o Setor de Operaçôes Estruturadas.

${ }^{230}$ MARTÍN, Adán Nieto; CALATAYUD, Manuel Maroto. Public compliance: prevención de la corrupción en las administraciones públicas y partidos políticos. Cuenca: Ediciones de la Universidad de Castilla-La Mancha, 2014. 
- Finanças públicas: travessia entre o passado e o futuro

É essencial, portanto, que a cultura corporativa ressoe na implementação dos programas de integridade, para que não perpetue estruturas fajutas que sirvam de anteparo para corrupção.

Voltando à Lei Anticorrupção, diferentemente da Lei de Lavagem de Dinheiro, o programa de integridade não é de implementação obrigatória. É dizer, não haverá consequências legais negativas caso determinada companhia decida assumir os riscos de não dispor de uma política interna de integridade. Ao invés disso, a lei objetivou estimular a aderência das empresas, possibilitando que elas respondam objetivamente (sem demonstração de culpa) por fraudes ou desvios relacionados à corrupção (art. 5\%), tanto na esfera administrativa, quanto judicial, sujeitando-as a severas penalidades, incluindo a hipótese de dissolução compulsória (art. 19, III), que equivale à morte da pessoa jurídica. Por outro lado, a lei estabeleceu como incentivo positivo que a comprovação acerca da existência de mecanismos e procedimentos internos de integridade, auditoria, incentivo à denúncia de irregularidades e a aplicação efetivo de códigos de conduta no âmbito da companhia - todos estes elementos inerentes ao programa de compliance - permitem aliviar até certo ponto as sanções administrativas previstas na lei, que correspondem à multa de 0,1 a $20 \%$ do faturamento bruto da empresa, além da publicação da decisão condenatória. Neste contexto, investir em um mecanismo seguro de atenuação da pena parece ser mais produtivo.

Em suma, o Estado brasileiro compartilhou com o setor privado a responsabilidade pela prevenção e detecção da corrupção, aumentando, por um lado, os custos da não conformidade e, de outro, os incentivos pela regulamentação da ética. A meta consiste em esclarecer dois pontos: o crime não compensa; a honestidade compensa.

Apesar dessa previsão inicial, entender perfeitamente o que a norma queria dizer com "procedimentos internos de integridade" permaneceu nublado até 2015, até que fosse publicado o Decreto n. 8.420/2015, regulamentando a Lei Anticorrupção e sanando algumas dúvidas. Nos arts. 41 e 42, o decreto delimitou quais mecanismos internos e diretrizes poderiam ser consideradas para fins de elaboração do programa de integridade, fornecendo ainda os parâmetros e orientações gerais que servem de base para avaliação de sua eficácia, além de determinar que a comprovada adequação do programa a estes parâmetros reduziria a dosimetria da penalidade administrativa em 1 a $4 \%$ (art. 18, V).

Em verdade, ao estabelecer uma referência legal com maiores detalhes sobre a aplicação do programa nas empresas - embora restem pontos escurecidos - o 
governo seguiu as recomendações internacionais. ${ }^{231}$ No entanto, mesmo com os esclarecimentos fornecidos pelo Estado, grande parte das empresas brasileiras ainda não se sensibilizaram para o aparelhamento dos programas de integridade. Ironicamente, o que parece estar surtindo maior efeito prático em relação às grandes empresas brasileiras, em particular aquelas encalacradas nos escândalos de corrupção massiva, é o compromisso forçado por meio dos acordos de leniência, instrumento semelhante à colaboração premiada da Lei n. 12.850/2013, mas destinado às pessoas jurídicas que pretendam confessar ilícitos em troca de benefícios.

No âmbito destes acordos, o Ministério Público Federal estabelece uma cláusula condicionando as vantagens pactuadas à obrigação da empresa a realizar investigações internas, e investir na readequação de suas atividades e padrões de integridade, a exemplo do acerto firmado com a Construtora Camargo Correa. ${ }^{232} \mathrm{O}$ Departamento de Justiça norte-americano (DOJ) previu item semelhante no acordo (plea-agreement) firmado com a Organização Odebrecht. ${ }^{233}$ Neste último, ficou assentado que a empresa brasileira aumentaria o número de funcionários responsáveis pelo setor de compliance em 50\%, assim como duplicaria o volume de recursos investidos na área em 2016, além de aceitar submeter-se ao monitoramento externo para aferir a eficácia do programa. Por este caminho eminentemente reativo tem-se conseguido implementar, na prática, aquilo que a letra da lei não conseguiu incutir. A pressão nestes casos é direta e acentuada, pois a constatação de que a empresa violou os termos do contrato (que é a natureza jurídica dos acordos de leniência), não investindo como deveria nas medidas de conformidade, tem consequências drásticas para ela, tais como: inabilitação para celebrar novo acordo por três anos; cobrança dos valores que foram atenuados do saldo da multa; vencimento antecipado das obrigações de pagamento previstas no acordo; possibilidade de utilizar as informações confessadas pela empresa.

231 United Nations Office on Drugs and Crime. An anti-corruption ethics and compliance program for business: a practical guide. United Nations, 2013, p. 34.

232 Acordo de Leniência MPF e Construtora Camargo Corrêa. Ação de improbidade administrativa 5a Vara Federal de Curitiba. Processo eletrônico n. 5006717-18.2015.4.04.7000.

$233 \mathrm{O}$ documento atesta a fragilidade dos mecanismos de compliance que já existiam no âmbito da Odebrecht: “(...) d. não obstante o fato de que o réu possuía controles anticorrupção inadequados e pouco ou quase-nenhum programa de compliance durante o período referente às condutas descritas no Relatório, o réu tem se comprometido a aprimorar o seu programa de compliance anticorrupção e os controles internos (...)". UNITED STATES DISTRICT COURT EASTERN DISTRICT OF NEW YORK. Plea Agreement. Cr. No. 16-643 (RJD). 
-• Finanças públicas: travessia entre o passado e o futuro

\section{Desenvolvimento de uma política de compliance: passos para um programa efetivo}

Como já sabemos, o programa de conformidade não pode ser um conjunto de documentos e estruturas desprovidas de eficácia prática. Deve-se inibir os programas insinceros, cuja finalidade seja exclusivamente esconder práticas ilegais sob as vestes de uma preocupação dissimulada com a ética. Mas como evitar que isso aconteça? Sob quais critérios tornar-se-ia possível avaliar se uma organização está genuinamente preocupada com o funcionamento do compliance? Como torná-lo eficiente?

Este livro, como já pôde notar o caro leitor, é eminentemente propositivo. Busco, a cada capítulo, trazer elementos que reputo serem essenciais à composição daquilo que chamamos ao início de programa brasileiro de controle preventivo; o tratamento correto para remediar a doença degenerativa que nos acomete há séculos: a corrupção. Aqui não será diferente. Para responder às perguntas acima, devemos conhecer os elementos de um programa de conformidade e como eles funcionam - ou deveriam funcionar.

Não custa recordar que estruturas de integridade adequadas possibilitam reduzir os riscos de violação ética e ineficiência da instituição, garantem credibilidade e confiança dos clientes, parceiros econômicos e partes interessadas, além de ajudarem na consolidação do jogo limpo, através de um ambiente de negócios ético e transparente.

Diferentemente do que vimos em relação aos reportantes e a carência de normas jurídicas sobre este assunto, o Brasil já dispõe de certa regulamentação a respeito do compliance, embora insuficiente. Por conta disso, a base das proposiçôes sobre as quais falarei em seguida constituirá um misto entre regras domésticas e internacionais. Do lado brasileiro, temos o Decreto n. 8.420/2015 e a Portaria n. 909/2015, da Controladoria-Geral da União, que dispóem sobre a avaliação de programas de integridade. ${ }^{234} \mathrm{Na}$ perspectiva internacional: o Guia Prático de Programa sobre Ética e Compliance Anticorrupção, das Naçôes Unidas (2013); ${ }^{235}$ o Manual para Empresas: Ética, Anticorrupção e Elementos de Conformidade,

${ }^{234} \mathrm{Na}$ medida em que não será abordado o aspecto especificamente criminal do compliance, não inclui na referência legal do trabalho a Lei n. 9.613/98 (Lei de Lavagem de Dinheiro), tampouco a Resolução n. 20, do Conselho de Controle de Atividades Financeiras, que dispóe sobre os procedimentos a serem adotados pelas empresas reguladas pelo COAF.

235 United Nations Office on Drugs and Crime. An anticorruption ethics and compliance programme for business: a practical guide. United Nations, 2013. 
elaborado em conjunto pela OCDE, Nações Unidas e Banco Mundial (2013); ${ }^{236}$ a Avaliação dos Programas de Compliance Corporativos, do Departamento de Justiça dos Estados Unidos e; ${ }^{237}$ a norma ISO 37001/2016, adotada pela ABNT, em 2017. ${ }^{238}$

Ressalto algumas observações preliminares importantes.

Primeiro: não cabe ao Estado-legislador detalhar como o programa de integridade será implementado na empresa, o que poderia levar à desatualização e inutilidade do instituto. A legislação apenas prevê as diretrizes e características essenciais, para ajudar no desenho do sistema. É a própria empresa que desenvolverá, num processo de autoconhecimento, as medidas internas de prevenção. Isto quer dizer que inexiste um pacote único de mecanismos que sirvam indistintamente para todas as organizações. Não! O tamanho, o volume de operações, a estrutura geográfica, área de atuação e, sobretudo, os riscos variam de empresa para empresa, o que influi diretamente na implementação do sistema. Por exemplo: a estrutura de integridade de uma grande organização do setor de infraestrutura terá contornos completamente distintos daquele introduzido por uma microempresa do ramo comercial. 239

Segundo e reafirmando: a existência do compliance, ainda que seja razoavelmente eficaz, não garante imunidade total aos riscos de corrupção e desperdício. Um único funcionário mal-intencionado possui potencial para acarretar um escândalo na corporação. Portanto, a integridade não constitui a morfina que alivia a dor nos momentos mais críticos, mas a rotina saudável que ajuda a evitar, embora não exclua completamente a possibilidade, a contração da doença.

Tais considerações permitem-nos entender melhor o propósito preventivo do programa de integridade, para então desenvolver seus elementos.

Um bom exemplo de sucesso dos programas de compliance na fortificação da ética empresarial está em Singapura. O pequeno país do sudeste asiático adquiriu

236 OCDE. Oficina de las Naciones Unidas contra la droga y delito, grupo del Banco Mundial. Ética anticorrupción y elementos de cumplimiento: manual para empresas, 2013.

237 U.S. Department of Justice. Criminal Division. Fraud Section. Evaluation of corporate compliance programs, 2017.

238 Sigla abreviativa para Organização Internacional de Normalização, entidade que congrega os grêmios de padronização/normalização de 246 países.

239 Com efeito, as Microempresas e Empresas de pequeno porte podem adotar um programa simplificado, dispensando alguns requisitos constantes do art. 42 do Decreto n. 8.420/2015, conforme Portaria Conjunta da CGU e Ministério da Micro e Pequna Empresa n. 2.279/2015. 
sua emancipação do Reino Unido há pouco mais de cinquenta anos. No período pós-independência, as fortes raízes colonizadoras não lhe permitiram libertar-se da corrupção sistêmica que impregnava as frágeis instituições singapurianas. Até a década de 1970, Singapura era extremamente pobre e uma das nações mais corruptas do planeta. Em seu livro de memórias, Lee Kuan Yew, liderança política que conduziu Singapura do terceiro ao primeiro mundo, narra o cenário com o qual se deparou, em 1959, quando se tornou primeiro-ministro: "corrupção, nepotismo, propinas e subornos são um meio de vida na Ásia, e as pessoas as aceitam abertamente como parte de sua cultura e costumes. (...)" ${ }^{240}$ A quebra de paradigmas deu-se raças à transformação das instituições, reconstruídas sob o alicerce da ética e da responsabilidade (accountability). Hoje, o país ocupa a $7^{\text {a }}$ posição no índice de percepção da corrupção para 2016, da Organização Transparência Internacional, à frente de países como Canadá e Alemanha, além de ser o $6^{\mathrm{a}}$ com maior renda per capita no mundo. Não por acaso, a Lei de Prevenção à Corrupção, de 1960 (revisada em 1993), relevou os deveres de integridade nas empresas, que atualmente gozam dos mais desenvolvidos sistemas de compliance.

Singapura, portanto, é um ótimo parâmetro caso desejemos analisar os elementos que conformam um bom sistema de integridade. Pensando nisso, o Escritório de Investigação da Corrupção (CPIB), órgão anticorrupção independente de Singapura, apresentou os quatro passos essenciais para o desenvolvimento sólido dos programas de conformidade: compromisso (pledge); avaliação (assess); controle e comunicação, e monitoramento (track). ${ }^{241} \mathrm{E}$ a trilha que seguiremos.

O passo inicial, do comprometimento, diz respeito à iniciativa da alta direção da empresa no sentido de implementar um conjunto de medidas internas que valorizem a cultura ética e aperfeiçoem a boa governança corporativa. Embora seja mais abstrato, este compromisso genuíno é fundamental, pois sinaliza a intenção da companhia de realizar negócios eticamente, fora do tradicional círculo vicioso. No capítulo referente à força do bom exemplo, vimos que a conduta daqueles que lideram com ética tem inequívoco efeito positivo sobre o comportamento dos indivíduos numa sociedade. $\mathrm{O}$ mesmo acontece no âmbito interno da companhia, na medida em que as atitudes da alta administração influenciam e são percebidas positiva ou negativamente pelos funcionários. Inevitavelmente, se o tom definido

240 KUAN-YEW, Lee. A história de Cingapura: Editora Globo, 1998.

241 PACT - A practical anticorruption guide for businesses in Singapore. Corrupt practices investigation bureau. Disponível em: <https://www.cpib.gov.sg/sites/cpibv2/files/PACT\%20 A\%20Practical\%20Anti-Corruption\%20Guide\%20For\%20Businesses\%20in\%20Singapore.pdf>. Acesso em: 7 jul. 2017. 
pelos diretores se alinha à integridade, os funcionários estarão mais inclinados a defender os mesmos valores. Por outro lado, se os superiores endossam práticas antiéticas e se concentram exclusivamente nos resultados obtidos, os empregados terão maiores incentivos para agir dessa forma, porque sentem que a conduta ética não constitui uma prioridade dentro da organização. $\mathrm{O}$ vício espalha-se rápido, quando o traz a autoridade, diria Shakespeare. Em virtude disso, os estudos sobre compliance denominam o engajamento da estrutura diretiva de tom do topo (tone from the top), pois representa a mensagem que será transmitida por todas as camadas da empresa.

Destaco, as palavras são inócuas se não forem traduzidas em ação. Quer dizer: o compliance deve estar inserido na agenda fixa da organização, como componente-chave nas operaçóes cotidianas. Cabe aos dirigentes incluir o tema nas prioridades estratégicas, assegurando sua inclusão no orçamento e demonstrando explicitamente que a companhia enaltece condutas éticas, por exemplo, ao exaltar a atitude de determinado funcionário que rejeitou uma oportunidade de negócios por ela estar vinculada ao pagamento de propina, mesmo que esta decisão tenha implicado prejuízos econômicos à empresa.

Infelizmente, a pressão para atingir metas efêmeras, o imperativo do faça seu trabalho e a necessidade de prover resultados positivos frequentemente leva à busca por atalhos, resultando em várias formas de corrupção e comportamentos antiéticos. Para que os funcionários tenham os incentivos corretos, a empresa deve assegurar uma cultura ética e aberta, na qual os membros são encorajados a fazer o certo e sentirem-se habilitados para desafiar decisões gerenciais ou metas que entendam ser antiéticas ou disfuncionais. Isso deve ser reforçado pela forte mensagem ética da alta administração.

Para mais, o tom não fica limitada ao topo. Deve ser igualmente expressado pelos diretores e gerentes intermediários (tone from the middle). Além disso, a mensagem do topo somente terá resultados caso a liderança demonstre viver de acordo com os padrões éticos que advogam. Muitas vezes, escândalos corporativos revelaram que as lideranças não seguiam os valores e padrões de conduta que professavam dentro da empresa.

O segundo passo concerne à avaliação dos riscos. Aliás, posso afirmar que este pedaço da caminhada será determinante para todas as etapas subsequentes, tamanha sua importância.

As avaliaçōes de risco foram empregadas pela primeira vez no século XVII, com o intuito de verificar a probabilidade de explosão de máquinas à vapor, refinando-se no decorrer dos anos para endereçar riscos variados, como a fusão de um 
reator nuclear ou mudanças climáticas. ${ }^{242}$ Uma avaliação de riscos anticorrupção estima as chances de uma organização experimentar um ou vários tipos de corrupção. Assim como a verificação dos riscos de explosão ou fusão nuclear constitui pré-requisito inadiável na elaboração de medidas para eliminar estes riscos, a avaliação de riscos anticorrupção provê as informações críticas que os tomadores de decisão no setor privado (e público, conforme veremos) precisam para desenhar um programa razoável de prevenção da corrupção.

A análise dos riscos é o que racionaliza o programa de integridade, pois lhe dá substância e permite priorizar certas áreas operacionais. Em essência, avaliar as vulnerabilidades consiste em identificar em que situações ou transações alguém relacionado à organização - um funcionário, membro, parceiro ou representante - tem incentivos para agir de forma antiética. O Código Penal Espanhol, reformado em 2015 para abrigar disposiçōes sobre compliance e responsabilização de pessoas jurídicas, de forma bastante simples, diz que analisar os riscos envolve identificar as atividades em cujo âmbito possam ser cometidos os delitos que devem ser prevenidos (art. 31 bis, 5, 1a).

Logicamente, a corrupção pode ocorrer em organizações de qualquer setor. A propósito, o Brasil tem demonstrado isso com rara maestria, em especial devido à sufocante burocracia estatal que ainda determina a realização dos negócios neste país, exigindo um sem-número de permissões, autorizações, licenças e o lobby corpo-a-corpo com funcionários públicos para operar em qualquer plataforma, o que seguramente deixa um campo aberto para o oferecimento de propinas e outras vantagens indevidas, na velha lógica da criação de dificuldades para venda de facilidades. O compliance é a melhor - senão a única - forma de reduzir o risco de engajamento em tais práticas e incentivar o jogo limpo.

Não obstante isso, alguns setores apresentam riscos mais intensos, tendo em vista fatores como: maior envolvimento com autoridades públicas, movimentação de produtos entre fronteiras, participação em contratos administrativos etc. Em 1999, a ONG Transparência Internacional elaborou o Índice de Pagadores de Propina (Bribe Payers Index), com a intenção de examinar o lado da oferta da corrupção, e identificar quais setores econômicos são mais propensos ao pagamento de propina. No último relatório, de 2011, os setores agropecuários, de tecnologia da informação, bancário, farmacêutico e do petróleo ficaram entre aqueles com risco mais acentuado para corrupção.

242 ZACHMANN, Karin. Risk in historical perspective: concepts, contexts and conjunctions. In: KLÜPPELBERG, C.; STRAUB, D.; WELPE, I. Risk - a multidisciplinary introduction. Springer: Cham, 2014. 
Os riscos externos são importantes, mas os olhos da empresa devem estar voltados às suas próprias vulnerabilidades. Por isso afirmei que este instrumento consiste, afinal, em um processo de autoconhecimento. $\mathrm{O}$ foco preliminar, portanto, deve estar no ambiente operacional da companhia, para saber quais atividades estão mais expostas à corrupção. Isso pressupõe identificar as principais áreas de funcionamento da empresa (p.ex.: distribuição, compras, contratos); os riscos inerentes a cada área funcional; os riscos mais significantes, examinando a probabilidade de eles ocorrerem em certo espaço de tempo e o impacto negativo (legal, reputacional e financeiro) que podem acarretar.

Além do mais, como a fraude e a corrupção são atitudes essencialmente racionais, a identificação dos riscos exige certo ceticismo da organização para se perguntar: como um agente corrupto conseguiria explorar as fraquezas do nosso sistema?

Os resultados da avaliação de riscos devem ser sistematizados de modo a permitir um exame panorâmico das áreas que demandam maior esforço preventivo. Assim como o naufrágio é o destino mais provável para uma embarcação à deriva, o programa de integridade que não comece por este levantamento, usualmente apelidado de mapa de calor (map of risk assessment), está fadado ao fracasso, pois sem ele dificilmente a empresa conseguirá estruturar medidas que reduzam de fato o risco de violações internas.

Dentro desta perspectiva inicial de análise, é importante também que a companhia entenda o comportamento que as leis e regulamentos domésticos e internacionais exigem dela. Em outras palavras, a empresa deve procurar saber como estão estabelecidas as regras do jogo. $\mathrm{O}$ emaranhado legislativo brasileiro, composto por uma variedade imensa de regras legais e infralegais torna particularmente difícil essa tarefa, quase heroica, eu diria. A conduta de uma companhia brasileira ou operante no Brasil está sujeita a diversas normas e ao escrutínio confuso de várias instituições de controle. Uma situação hipotética de fraude à licitação pública empreendida por funcionários de uma companhia aciona, ao menos, quatro diplomas: a Lei de Licitaçõos e Contratos Administrativos (8.666/93); a Lei Anticorrupção (12.846/2013); a Lei de Defesa da Concorrência (12.529/2011) e a Lei de Improbidade Administrativa (8.429/92), com múltiplas regras sobre ressarcimento, multa, inidoneidade, inabilitação e outras penalidades. Ademais, o mesmo fato desperta competências superpostas de órgãos que exercem o controle público. Somente no âmbito federal, teríamos: CGU, AGU, TCU, MPF, PF, Cade e CVM. Obviamente, o número expressivo de órgãos fiscalizadores da coisa pública é um fator institucional e republicano positivo, porém o ambiente conturbado que decorre da falta de coordenação entre eles gera uma insegurança que dificulta, por 
exemplo, a avaliação de risco da empresa. Este cenário repercute atualmente no âmbito dos acordos de leniência, trancados em sua maioria devido ao impasse existente entre o Tribunal de Contas da União, Advocacia-Geral da União e Ministério Público Federal, sobre quem deveria firmar os acordos.

No tocante aos acordos de leniência provenientes da Operação Lava-Jato, algum avanço foi obtido no sentido de coordenar as decisões dos organismos de fiscalização, particularmente entre o Tribunal de Contas e o Ministério Público Federal. ${ }^{243}$

Enfim, identificar os pontos de fragilidade interna e os regramentos que se aplicam às operações da empresa viabiliza a capacidade de prevenção do programa de integridade, que funcionará mais como um seguro contra a corrupção e a ineficiência.

Além do mais, a avaliação de riscos deve ser dinâmica, justamente porque os riscos são dinâmicos. Análises esporádicas podem até ser úteis a curto-prazo, mas não conseguirão capturar com eficiência as mudanças operacionais que certamente ocorrerão. Ora, se a empresa decide expandir suas atividades para outro país, novos empregados deverão ser contratados, novos setores emergirão e novas leis e regulamentos deverão ser observados, o que implica necessariamente novos pontos de vulnerabilidade a serem identificados e, por conseguinte, mitigados. Portanto, deve haver uma base-temporal fixa que possibilite o constante aprimoramento e adaptação do programa. Aqui, vale a máxima de Heráclito, segundo a qual nada é permanente, senão a mudança. É igualmente relevante que todo este processo seja documentado, com vistas a qualificar a fiscalização e prover uma base para avaliações futuras.

Uma vez identificadas as áreas potencialmente problemáticas, a implementação do programa de compliance poderá ser deflagrada, visando minimizar a ocorrência de violações e, caso elas ocorram, demonstrar que a responsabilidade pela ilicitude está associada a um agente ou empregado imoral, não se tratando de um problema sistêmico na empresa. Desta forma, o desenho das políticas e procedimentos que integram o sistema de integridade possibilitará a construção de uma cultura ética de governança corporativa.

${ }^{243} \mathrm{Na}$ análise dos contratos de Angra 3, o TCU sobrestou a sanção de inidoneidade para participar de licitações que aplicaria às empresas Construções e Comércio Camargo Corrêa; Construtora Andrade Gutierrez e Construtora Norberto Odebrecht, tendo em vista que haviam firmado Acordo de Leniência com o MPF. No Acórdão n. 483/2017 - TCU - Plenário, o Ministro Relator, Bruno Dantas, assim consignou: “os princípios da segurança jurídica e da proteção da confiança exigem que as instituições estatais atentem para o compromisso assumido nos acordos de leniência celebrados com outros órgãos (...)". 
O tratamento da corrupção está geralmente associado a questôes morais, porém o compliance anticorrupção também tem uma dimensão pragmática. Isso pode ser menos óbvio em países onde a propina e o jeitinho estão mais disseminados, mas pensar estrategicamente em como prevenir a corrupção no setor privado vale a pena como modelo de negócios. Aliás, a redução dos riscos de corrupção em transações comerciais aumenta a qualidade e reduz o custo dos produtos, retém empregados qualificados e atrai parceiros que também valorizem a ética, sinalizando uma vantagem competitiva, de modo que o ciclo comece a girar na direção correta.

A princípio, tais afirmações podem soar demasiadamente genéricas, contudo, têm alguma sustentação empírica, na medida em que a avaliação de comportamento ético das empresas em determinados países, capturada pelo Fórum Econômico Mundial, tem forte correlação com os índices de percepção de pagamento de propina. Empresas de países onde a ética corporativa é vista como fortemente estimulada são percebidas como menos propensas ao suborno.

Digo isso pois em geral as corporações não se preocupam em estabelecer valores éticos e difundi-los entre seus funcionários e intermediários, supondo que constituiria um fator de desvantagem em relação às empresas que operam no mercado clandestino da corrupção, o que não corresponde à verdade.

Negligenciar a essencialidade em esclarecer quais princípios regem as atividades da empresa significa ignorar os contornos éticos que existem no processo de tomada de decisões e o que determina escolhas morais ou imorais pelos funcionários. Neste sentido, as organizações não podem deixar de fomentar decisões acertadas do ponto de vista ético, quer dizer, que estejam consonantes com o que se entende por integridade.

Para tanto, estes valores precisam ser objetivados ou traduzidos em políticas (princípios) e procedimentos (regras) que consolidem a cultura corporativa através da prática ética cotidiana. Este processo de objetivação dos valores, de individualização do genérico, cabe aos códigos de conduta.

Muito se fala (e se tem falado) sobre estes códigos, mas pouco se faz para entender realmente a sua importância na estratégia de prevenção da corrupção e estímulo à governança ética da empresa. Penso que este mecanismo possui alguns aspectos comportamentais - ou psicológicos - que não podem passar desapercebidos.

O primeiro deles diz respeito à teoria da associação diferencial, defendida por Edwin Sutherland, a quem se lhe atribui a criação do termo criminalidade do colarinho-branco. ${ }^{244}$ Segundo ele, comportamentos antiéticos são aprendidos pela asso-

244 EDWIN, SUTHERLAND. White-collar criminality. American Sociological Review, Washington, v. 5, n. 1, 1940, p. 1-12. 
ciação direta ou indireta com aqueles que se comportam de modo semelhante. Em outras palavras: É do convívio com outras pessoas que pautamos nossa conduta e nossos valores. Os desvios morais decorrem então da aprendizagem proporcionada por ambientes onde os princípios éticos não estão claros e são reiteradamente desrespeitados. Este cenário prepara o terreno para o afastamento dos funcionários da esfera de respeito às normas, e aqueles que remanescem apegados à honestidade geralmente sentem-se marginalizados e têm poucos motivos para manter uma estabilidade ética. ${ }^{245}$

O processo de tomada de decisão pressupõe o conhecimento moral, que representa basicamente a habilidade de encaixar informações em categorias morais, desenhando com nitidez o risco que separa o certo do errado. Se o indivíduo não conhece a dimensão moral de uma decisão em jogo, ele certamente deliberará orientado apenas pelas possíveis vantagens (indevidas ou não) que possam advir, a despeito de qualquer preocupação ética.

Para compreender melhor a dimensão moral das decisões e neutralizar aquele processo de aprendizagem por associação (diferencial), os indivíduos precisam perceber claramente quais são os valores que integram o grupo do ponto de vista normativo. Aí entra o código de conduta. ${ }^{246}$

Em síntese, o código representa o regulamento específico que externará os valores que nortearão a arquitetura de escolha dos empregados e o relacionamento com terceiros (parceiros, fornecedores, contratantes, intermediários, stakeholders etc.), detalhando os comportamentos esperados e as condutas vedadas, conforme a política de proibição pregada pela administração. Falo em específico, pois as disposiçôes devem ser elaboradas tomando em conta a complexidade estrutural e os riscos existentes em cada setor.

É a política de proibição ou intolerância a desvios éticos, nome dado pela Convenção das Nações Unidas contra a Corrupção, que definirá os padrões ou standards de comportamento aplicáveis caso a caso. O ambiente negocial é extremamente complexo. Nem todas as atividades têm contornos nítidos, e a distinção entre condutas éticas e a corrupção pode ser bastante imprecisa, graças à tenuidade

245 PIMENTEL, Manoel Pedro. O crime de colarinho branco. Revista da Faculdade de Direito da Universidade de São Paulo, v. 68, n. 1, 1973.

${ }^{246}$ A fim de evitar controvérsias jurídicas, preferi extrair do contexto principal a questão referente à eficácia jurídica destes códigos de conduta empresariais. Acredito que, inobstante as companhias privadas não disponham de poder normativo unilateral, ao emanar suas disposições éticas de um autêntico poder jurídico (poder de direção do empresário), criam obrigações para o empregado, regulando a esfera de atuação devida por este. 
entre costumes e práticas enraizadas no modelo de negócios. É comum encontrar organizações cuja tradição inclui procedimentos antiéticos ou corruptos, mas que por constituírem praxe da empresa, não são percebidos desta forma. $\mathrm{O}$ código de conduta, resolvendo essas áreas cinzentas e desenhando uma linha clara entre práticas legítimas e ilegítimas de acordo com os valores adotados, serve como um guia inequívoco e "desambiguador" do modelo de conduta ética.

$\mathrm{Na}$ verdade, deixa-se claro como serão tratadas as manifestaçóes relevantes de corrupção (já que uma definição objetiva é difícil), que foram identificadas na avaliação de riscos, traduzindo o escopo da política em elementos práticos.

Inquestionavelmente, a propina é a manifestação mais usual da corrupção. De acordo com o relatório de 2017 do Barômetro Global da Corrupção sobre a América Latina, elaborado pela Transparência Internacional, 90 milhões de pessoas, distribuídas em 20 países pesquisados, tiveram que subornar agentes públicos em 2016 para obter serviços públicos básicos. As empresas não estão fora deste cenário, embora o seu envolvimento esteja mais associado ao patrimonialismo (rent-seeking), conforme temos visto no Brasil, alimentando campanhas políticas e recebendo vantagens às custas do patrimônio do Estado. Estes pagamentos de facilitação, a fim de driblar a burocracia ou fugir da competição justa, parecem ter se convertido em condição necessária para fazer negócios ou participar de licitações públicas. Aqueles que se abstém de pagar enfrentam severas desvantagens, principalmente porque ficarão isolados, enquanto o mercado clandestino funciona a todo vapor. $\mathrm{O}$ quadro é particularmente desafiador para as micro e pequenas empresas, que percebem estas taxas de corrup̧̧ão como uma medida de sobrevivência, pois têm capacidade limitada de redução da demanda. Mesmo assim, o risco de sucumbir ao ciclo vicioso da propina deve estar consignado na política de integridade da empresa, e o código precisa prever medidas para reduzi-lo. De início, é necessário prover uma definição clara e detalhada do que constitui pagamento de facilitação, afastando quaisquer dúvidas ou zonas cinzentas acerca da sua legitimidade. Por conseguinte, conhecendo os setores internos onde esses pagamentos são mais prováveis e podem causar maiores impactos, é aconselhável que essas áreas estejam submetidas a treinamentos mais intensos e regras específicas de comportamento.

As falcatruas não se limitam à verba que sai de mão-em-mão, incluindo também formas não monetárias. A despeito dos recentes episódios envolvendo malas, caixas, cuecas e apartamentos abarrotados de dinheiro-vivo, o modus operandi com transaçôes em espécie já está démodée. Desvios disfarçados de contribuição filantrópica, despesas promocionais, financiamento de campanha política, têm se tornado cada vez mais comuns, dificultando, inclusive, o trabalho de investigação e 
consequente punição destas práticas, justificando o tratamento eminentemente preventivo-interno. Em seguida, mencionarei alguns dos principais riscos de manifestação da corrupção não monetária e como devem ser tratados no âmbito do programa de integridade.

Inicialmente, tem-se aquilo que a ONG Transparência Internacional denomina de despesas promocionais, que incluem presentes (bens e serviços), hospitalidade e despesas diversas. Em geral, essas despesas são percebidas como uma forma legítima de melhorar a imagem e as relaçôes comerciais da empresa, integrando uma tradição ou rotina da companhia, mas podem constituir uma área de risco relevante na organização, pois constantemente servem de anteparo à corrupção. Sobre o assunto, o sociólogo francês Marcel Mauss afirma que o ato de conceder presentes cria um vínculo social, geralmente com obrigações recíprocas ao destinatário, já que os objetos nunca estão completamente dissociados da pessoa que lhes fornece. É o que temos visto recorrentemente acontecer no Brasil: políticos utilizando jatinhos de empresários, reformas particulares milionárias pagas por empresas que possuem contratos com o governo, intermediaçóes na compra de bens para a lavagem de dinheiro. Seguindo a trilha marcada pela avaliação específica de riscos, a empresa poderá delimitar onde estes gastos promocionais são mais provavelmente utilizados como subterfúgio à ética, sobretudo nas áreas que se relacionam com funcionários públicos e empregados de empresas estatais. Nestes casos, o código de conduta pode prever limites importantes como o estabelecimento de tetos nominais concernentes ao valor do benefício oferecido ou recebido, e a necessidade de autorização prévia do setor financeiro para despesas que ultrapassem esta restrição. A regra, no entanto, deve ser de proibição das despesas que possam influenciar decisões.

Outro ponto crítico presente no relacionamento empresarial com o setor público diz respeito aos conflitos de interesses, que emergem quando compromissos pessoais do indivíduo influenciam nas suas decisões. O conflito em si não envolve necessariamente práticas corruptas ou fraudulentas, embora possa desencadeá-las, quando dão ensejo à oportunidade de beneficiar um parente ou amigo. Ainda que não haja um ato estritamente ilegal proveniente deste conflito de interesses, a percepção pública pode ser diferente, presumindo um viés de favorecimento ilegítimo das decisões. Para evitar isso, primeiro deve-se prover uma definição clara sobre conflito de interesses, com exemplos práticos que facilitem o entendimento e eliminem quaisquer interpretações controvertidas. Em seguida, se esgueirando no levantamento de riscos, a companhia deve manter um registro atualizado das áreas que estão particularmente propensas aos riscos de conflitualidade. Situações exemplares referem-se ao sócio de empresa que integra a comissão permanente de licitação 
do órgão contratante; a movimentação de agentes entre o setor público e privado (revolving-door); a contratação de parentes ou amigos de agentes públicos para obter vantagens econômicas, como no caso da JPMorgan, que em 2016 teve que pagar US \$ 264 milhôes em penalidades, devido à contratação de filhos de agentes governamentais chineses com o propósito de influenciar decisões e obter negócios naquele país. ${ }^{247}$

Igualmente problemático, é a questão do engajamento político das empresas. Em especial no Brasil, essa espécie de envolvimento serviu de fachada à distribuição de dinheiro sujo para campanhas eleitorais em troca de benefícios legislativos (desoneraçōes tributárias, regimes aduaneiros especiais, subsídios públicos) e contratos superfaturados, revelando a relação desonesta que há entre o setor empresarial e os políticos. Nas grandes operações anticorrupção em curso no país, ficou constatada uma estrutura semelhante, formada por quatro núcleos: o núcleo político (partidos e agentes políticos); o núcleo econômico (empresas); o núcleo administrativo (funcionários da administração pública); e o núcleo financeiro (operadores financeiros e doleiros). O núcleo econômico financia os integrantes do núcleo político, que respondem com vantagens direcionadas aos grupos de interesse financiadores, em detrimento do interesse público. Claro que esta é uma forma muito resumida (e insuficiente) de descrever o funcionamento real do sistema político brasileiro, embora não deixe de ser verdadeira. A contínua influência econômica no processo político, ou capitalismo da camaradagem, afeta a confiança tanto no lado da demanda (políticos), como da oferta (empresas), razão pela qual o Supremo Tribunal Federal (ADI 4.650), em 17 de dezembro de 2015, declarou inconstitucional a doação por pessoas jurídicas a campanhas eleitorais, antes permitida pela Lei n. 9.096/95. Se engana, todavia, quem acredita que a decisão da Suprema Corte pôs um ponto final nesse problema e por isso ele não precisa ser discutido nos programas de integridade. Duas razões justificam, a meu ver, a contínua preocupação com a questão do financiamento político nas empresas: a) possibilidade (não alterada pela minirreforma eleitoral de 2017) de doação por pessoas físicas, o que permite mascarar contribuições empresarias milionárias; b) a realização de doaçôes não contabilizadas (caixa-dois), ainda massivo nos certames políticos. As companhias que pretendam fugir deste ciclo vicioso devem fortalecer a transparência e estabelecer políticas internas claras referentes às doaçôes políticas, como limites

247 PROTESS, Ben; STEVENSON, Alexandra. JPMorgan Chase to Pay \$264 Million to Settle Foreign Bribery Case. The New York Times. Business, November, 17 de 2016. Disponível em: <https://www.nytimes.com/2016/11/18/business/dealbook/jpmorgan-chase-to-pay-264-million-to-settle-foreign-bribery-charges.html>. Acesso em: 12 out. 2017. 
financeiros e perfilhamento ideológico específico - no Brasil, era comum que empresas financiassem 5, 10 e até 15 agremiações diferentes. Outras medidas, tal qual a instituição de fundos cívicos, demonstram um engajamento político responsável da companhia e contribuem para o desenvolvimento e renovação ética da política nacional. Ainda na seara política, é importante que os próprios partidos políticos, para os quais entendo que se aplica a Lei Anticorrupção, implementem seus próprios programas de integridade, a fim de resguardar a moralidade na atividade política.

Aspecto crucial da política anticorrupção materializada no compliance, além das disposições acima traçadas, concerne à relação da companhia com terceiros. Vale lembrar que a Lei Anticorrupção trouxe penalidades pesadíssimas (incluindo, em sede judicial, a dissolução compulsória da empresa) e uma responsabilidade que independe da avaliação de culpa, isto é, basta um fornecedor realizar um desvio que beneficie a empresa contratante para que esta seja condenada, independentemente se desconhecia ou não a ilegalidade. É a chamada responsabilização por associação (third party liability), vinculando de forma solidária a organização beneficiária do ilícito e suas controladoras, controladas, coligadas e consorciadas, o que ressalta a necessidade de examinar cuidadosamente as empresas parceiras. ${ }^{248}$

Permitir a ocorrência de ilegalidades, por funcionários ou fornecedores, para depois argumentar que medidas internas foram adotadas a posteriori, não caracteriza a efetividade que se exige do sistema de integridade. Portanto, merece atenção especial as práticas de due diligence, destinadas a conhecer o passado e presente das organizaçōes parceiras, reunindo informações sobre seus proprietários, bem como possíveis alertas vermelhos (red flags) que possam indicar riscos futuros de corrupção ou ineficiência. Uma empresa registrada em um paraíso fiscal ou que requeira pagamentos realizados exclusivamente em espécie, impedindo a emissão de registros das transaçôes, disparam o radar do compliance e, por isso, devem ser evitadas.

Também é possível estimular o comportamento ético através dos procedimentos de due diligence, em especial ao frustrar parcerias com empresas que não estejam alinhadas com os instrumentos de integridade, como o código de conduta estabelecendo uma política anticorrupção. Afinal, o objetivo é que os potenciais parceiros possam dizer: estou confiante que esta organização não adota práticas corruptas e posso demonstrar para outras pessoas que minha confiança é legítima.

Aliás, a determinação de cláusulas de compliance nos contratos da empresa, pelas quais os fornecedores e demais contratantes se obrigam a cumprir as regras

${ }^{248}$ É o que prevê o art. $4^{\circ}, \$ 2^{\circ}$, da Lei n. 12.846/2013. 
do código de conduta da empresa, incentiva boas práticas, permitindo a formação de uma rede positiva crescente - fora do mercado clandestino e vicioso - que adota condutas responsáveis. Esse movimento, se adotado pelas multinacionais, tende a acelerar o espalhamento da cultura ética no mundo corporativo, tornando o compliance, para além de um mecanismo específico anticorrupção, uma condição específica para realizar negócios no Brasil. Para sobreviver no mercado - obtendo empréstimos, tendo créditos avalizados, recebendo investimentos - as empresas terão de implementar mecanismos de conformidade.

Não é um cenário improvável, principalmente se contarmos com a cooperação ativa das grandes empresas, o que já vem acontecendo de modo incipiente. Mas ainda devemos superar a relutância decorrente do tradicional sempre foi assim; sempre tivemos este tipo de relacionamento com as companhias parceiras ou agentes públicos mais próximos; não queremos constrangê-los com este negócio de código de conduta! Instaurar uma cultura íntegra de verdade começa pela negação destes e outros costumes brasileiros, tão nocivos à ética.

Embora uma política anticorrupção cuidadosamente objetivada no código de conduta seja, de fato, uma peça-chave na prevenção dos desvios éticos, ela é insuficiente. Nenhuma companhia é completamente imune à corrupção. O que determina se a empresa terá ou não sucesso em conter estas irregularidades é o modo como apura e responde a elas, motivo pelo qual controles internos efetivos devem complementar a estrutura do programa de compliance. Afinal, como ressaltei ao início, conformidade tem a ver com avaliação, apuração e resposta.

Trata-se, portanto, do estabelecimento de um processo para apuração de violaçôes ao programa de integridade (incentivo) e dos critérios para sancionar violações ao código de conduta (enforcement). À vista disso, a empresa deve definir três coisas.

Primeiro, quais procedimentos serão adotados para investigar e detectar infrações relacionadas à corrupção, como a abertura dos canais de denúncia que protejam a confidencialidade dos reportantes (whistleblowing), a respeito dos quais falamos bastante no capítulo anterior, e a reavaliação dos procedimentos de autorização na companhia por mais de um indivíduo, método conhecido como princípio dos quatro-olhos. Esta fase é importante, pois permite manter cintilante o efeito dissuasório decorrente da percepção de que os mecanismos de detecção estão funcionando.

Segundo, de que maneira a empresa se comportará frente às violações detectadas, independente se caracterizam ou não delitos criminais, ou seja, como as infrações serão tratadas internamente. A lei anticorrupção não obriga que a companhia comunique as irregularidades às autoridades (Ministério Público, Polícias), 
mas valoriza a cooperação (art. 70, VII) e a comunicação espontânea antes da instauração do processo administrativo de responsabilização (art. 18, IV). Por outro lado, este modo de tratar violações implica definir as penalidades internas aplicáveis, pois a fixação de limites ao comportamento desassociado do poder coativo é como ter dentes e não poder morder. ${ }^{249}$ Caso contrário, os funcionários poderiam interpretar a ausência de penalidades sérias como um convite para que eles não conformem suas condutas às previsões do código.

Por fim, deve-se reservar atenção à institucionalização, é dizer, ao assentamento das responsabilidades pelo desempenho e controle interno no programa de integridade. Com efeito, várias empresas brasileiras já estão formando departamentos específicos de conformidade, usualmente chefiados pelos Diretores de Conformidade ou Compliance Officers, responsáveis por assegurar o cumprimento das regras éticas nas empresas, bem como as Comissões de Ética, que apuram e sancionam eventuais violaçôes ao código de conduta. Todavia, criar unidades próprias de compliance pode representar um empecilho, especialmente para micro e pequenas empresas, na medida em que essas estruturas (físicas e de pessoal) custam caro. Nos Estados Unidos, conforme pesquisa realizada pela Glassdoor - um site com listas de emprego e avaliações de empresas - a média salarial dos diretores de compliance é de US\$ 132.000 anuais. ${ }^{250}$ A Petrobrás, por exemplo, anunciou, em 2016, que gastaria cerca de $\mathrm{R} \$ 200$ milhões com a contratação de dois escritórios de advocacia para realização de investigações internas.

Mais importante, contudo, no desenvolvimento dos controles internos, é valorizar o aprendizado proporcionado pela evidenciação das fragilidades na empresa. Examinar como ocorreram violações éticas é, aliás, uma forma de avaliar os riscos e como eles se manifestam. Assim, a companhia não deve ser limitar à punição dos infratores, mas buscar as causas-raízes (root-causes) do problema.

Pois bem, obedecidas estas etapas, o programa de conformidade está em pleno funcionamento. A alta administração demonstra compromisso com as ferramentas de integridade, os riscos foram devidamente analisados e embasaram a elaboração da política anticorrupção materializada no código de conduta, bem como a estruturação dos controles internos. Parece que, diante disso, restaria acionar o piloto automático e aguardar o desenvolvimento natural da cultura ética. Não é bem

249 TERMES, I; ANGLÉS, F. El Código de Ética. Normas básicas para su diseño en la Administración Pública. Barcelona: Ediciones Gestión, 2000.

250 CASSIN, Richard L. How much do chief compliance officers make? FcpaBlog, October 16, 2017. Disponível em: <http://www.fcpablog.com/blog/2017/10/16/how-much-do-chief-compliance-officers-make.html>. Acesso em: 16 out. 2017. 
assim. O sistema de integridade não funciona por si mesmo, no standby, motivo pelo qual o seu andamento deve ser continuamente monitorado. É o último passo da nossa caminhada rumo às escolhas éticas na empresa: o monitoramento.

Isto é, a avaliação permanente da performance dos controles internos, da avaliação de riscos, buscando contínuo aperfeiçoamento do programa. Quem desempenha estas funções é a unidade de auditoria interna (formada por supervisores da própria empresa) ou externa (formada por escritórios especializados), que irá avaliar principalmente a aderência dos funcionários e terceiros à política de intolerância à corrupção. Há quem defenda, inclusive, que seria possível auditar a cultura ética da companhia, através de pesquisas e dinâmicas de grupo. ${ }^{251}$

Os aspectos básicos do programa de compliance estão postos. Ter apresentado os quatro passos não significa que a caminhada está encerrada, senão que ela apenas começou. À essa altura creio que os brasileiros não mais são iludidos por fórmulas prontas e panaceias que prometam resolver os seus problemas mais crônicos, como é a corrupção. Assim, o caminho até uma cultura ética consolidada, de respeito às leis e na qual prevaleça o fazer o certo por conviç̧ão, é longo, desgastante e sinuoso, mas transitável.

Despertar a consciência das entidades do setor privado de que a conduta ética não constitui uma desvantagem competitiva, senão uma condicionante necessária à realização de negócios poderá reverter o jogo sujo que prevalece hoje. Para tanto, é importante identificar as empresas que estão desalinhadas com os valores morais, isolando-as, naturalmente, do círculo comercial, contribuindo para que este tipo de maçã podre desapareça aos poucos, na medida em que a raiz é oxigenada.

251 Frances McLeod sugere que a auditoria sobre cultura seria possível mediante pesquisas intermitentes com empregados, clientes e líderes da organização. MCLEOD, Frances. We need to audit culture change too. The FCPA Blog Disponível em: <http://www.fcpablog.com/blog/2017/7/6/ frances-mcleod-we-need-to-audit-culture-change-too.html>. Acesso em: 6 jul. 2017. 
